\title{
HIV risk behaviors and sociodemographic features of HIV- infected Latinos residing in a new Latino settlement area in the Southeastern United States
}

\author{
Ann M. Dennis ${ }^{a,{ }^{*}}$, Jennifer B. Wheeler ${ }^{\mathrm{b}}$, Erik Valera ${ }^{\mathrm{c}}$, Lisa Hightow-Weidman ${ }^{\mathrm{a}}$, Sonia \\ Napravnik $^{a, b}$, Heidi Swygarda ${ }^{a}$, Clare Barrington ${ }^{d}$, and Joseph J. Eron ${ }^{a, b}$ \\ aDivision of Infectious Diseases, University of North Carolina, Chapel Hill, NC, USA \\ bDepartment of Epidemiology, University of North Carolina, Chapel Hill, NC, USA \\ 'Latino Commission on AIDS, New York, NY, USA \\ dDepartment of Health Behavior and Health Education, University of North Carolina, Chapel Hill, \\ NC, USA
}

\section{Abstract}

The Southeastern United States (US) has a rapidly growing Latino population, yet little is known about HIV-infected Latinos in the region. To help inform future prevention studies, we compared sociodemographic, clinical, and behavioral characteristics between immigrant and US-born HIVinfected Latinos using face-to-face interviews conducted at three clinics in North Carolina. Questions encompassed HIV testing, acculturation, sexual- and substance-related behaviors, and migration history. Behavioral data were compared with 451 black and white clinic patients. Differences were tested using Pearson's and Kruskal-Wallis tests. Participants $(n=127)$ were primarily male (74\%) and immigrants (82\%). Most immigrants were Mexican (67\%), had low acculturation scores (92\%), and were diagnosed a median of 8 years (IQR 0-12) following immigration. Compared with US-born Latinos, immigrants had lower CD4 counts at clinic entry (median 187 vs. 371 cells $/ \mathrm{mm}^{3}$ ) and were less likely to have graduated high school (49\% vs. $78 \%$ ) or have insurance (9\% vs. 52\%; all $P<0.05$ ). Most immigrants identified as heterosexual $(60 \%)$ and reported fewer lifetime partners than US-born Latinos (median 6 vs. 20; $P=0.001$ ). Immigrant men were less likely to report sex with men than US-born men (43\% vs. $81 \% ; P=$ 0.005). Immigrant men also had similar risk behaviors to black men, and US-born Latino men exhibited behaviors that were more similar to white men in our clinic. At the time of survey, $>90 \%$ of participants were receiving antiretroviral therapy (ART) and most had achieved HIV RNA $<50$ copies $/ \mathrm{mL}$ (62\% immigrants vs. $76 \%$ US-born; $P=0.32$ ). In conclusion, Latino immigrants were more likely to present with advanced disease, identify as heterosexual, and report different risk behaviors than US-born Latinos, yet receipt and response to ART were similar between the two groups. Prevention strategies should prioritize finding innovative methods to reach Latino immigrants for routine early testing regardless of risk stratification and include programs targeted toward the different needs of immigrant and US-born Latinos. 


\section{Keywords}

Hispanic; HIV; CD4 lymphocyte count; Southeast United States; immigrants

\section{Introduction}

Latinos are disproportionately affected by HIV/AIDS in the Southeastern United States (US), where they represent a rapidly growing segment of the population. With a Latino population increase of 394\%, North Carolina (NC) had the fastest-growing Latino population among all US states from 1990 to 2000 (Kochhar, Suro, \& Tafoya, 2005). By 2010, NC had the sixth highest proportion of foreign-born Latinos among all US states (Pew Hispanic Center, 2010). Simultaneously, the number of HIV/AIDS cases among Latinos also increased dramatically. Latinos accounted for only $1 \%$ of reported HIV cases in NC in 1995 (NC Department of Health and Human Services, 2000) which increased to $8 \%$ by 2009, with an incidence rate nearly four times higher than non-Latino whites (NC Department of Health and Human Services, 2010).

Despite the demographic shifts in the Southeast, there has been a paucity of research in the region focusing on Latinos living with HIV/AIDS. In a recent analysis, Latinos were more likely to present to care with advanced HIV disease compared with both blacks and whites (Dennis, Napravnik, Seña, \& Eron, 2011) - a finding hypothesized to result from a complex interplay of social factors including immigration status (del Rio, 2011). Importantly, little is known about Latinos in the Southeast in the context of risk behaviors, country of origin, and migration patterns (Painter, 2008). Compared with other US regions, Latinos in the Southeast are more likely to be foreign-born, male, and to have arrived after 1995, often unaccompanied by female partners (Kochhar et al., 2005). These recent immigrants may lack social support systems and stable sexual networks that are found in well-established Latino communities (2008). While these differences could lead to increased risk-taking behaviors (2008), they may also impact engagement in HIV testing and care. In addition, the language barriers faced by these immigrants may be substantial, with over half estimated to have little t o no English-speaking skills (Kochhar et al., 2005).

HIV research in regions with well-established Latino populations may not be directly translatable to new Southeastern Latino settlement areas such as NC, which may have more immigrant-rich Latino populations, and lag in the development of culturally and linguistically acceptable healthcare and outreach programs. The objectives of this study were to assess the sociodemographic, clinical, and behavioral features of HIV-infected Latinos receiving care in $\mathrm{NC}$ and to determine whether significant differences exist by immigrant status and in comparison with non-Latino black and white patients. A better characterization of risk behaviors and social barriers among Latino subgroups in the region will help inform more effective interventions such as targeted HIV prevention, testing, and linkage to care strategies. 


\section{Methods}

\section{Study population and recruitment}

We performed the face-to-face structured interviews from February 2010 to August 2011 at three HIV clinics. The sites included the University of North Carolina Infectious Diseases (UNC) Clinic (located in a large tertiary care facility serving over $2000 \mathrm{HIV}$-infected patients from a large surrounding rural and metropolitan catchment area) and UNC-affiliated Durham and Wake County Health Department clinics (serving approximately 400 and 1000 HIV-infected residents of these metropolitan counties, respectively). Eligible subjects were $\geq 18$ years of age, receiving HIV care, able to provide informed consent, and self-identified as Latino/Hispanic (defined as a person of Mexican, Puerto Rican, Cuban, South or Central American, or other Spanish culture or origin, regardless of race). This study was approved by the UNC Institutional Review Board.

Participants were recruited during routine clinical visits and interviewed in a confidential location within the clinic. All interviews were conducted by a bilingual interviewer who is of Mexican and Cuban descent and has extensive experience in working with HIV-infected and at-risk Latinos. Interviews lasted approximately 60 minutes and were conducted in Spanish, English, or both languages depending on patient preference.

\section{Measures}

Sociodemographic and migration characteristics—Demographic variables collected included educational attainment, annual income, marital status, current employment, insurance status, and history of incarceration. The Short Acculturation Scale for Hispanics (SASH) was administered (Marin, Sabogal, Marin, Otero-Sabogal, \& PerezStable, 1987). The SASH is a 12-item instrument assessing language, media preference, and ethnic social relations with scores for each item ranging from 1 (Spanish only or low US acculturation) to 5 (English only or high US acculturation). We defined "low acculturation" as a mean score <3.0 (Marin et al., 1987). Participants were asked about HIV testing history including year and location of HIV diagnosis and length of time from diagnosis to entering HIV care. Migration history was obtained starting with birth country and state (Mexico or US), date of immigration, frequency of return visits to originating country, and perceived country of infection.

Behavioral characteristics-Participants were asked about perceived mode of HIV infection, sexual orientation (including level of comfort), age at sexual debut, number of lifetime male and female sex partners, recent sexual partnership characteristics (in the past 3 months), and history of sexually transmitted infections. Exchange sex was asked through a series of questions about whether they had paid for or exchanged sex for money or goods. We asked whether these encounters had occurred both within and outside the US and about the gender and race/ethnicity of their typical partners. Detailed questions were asked about regular substance use including history of and recent illicit drug use (cannabis cocaine/crack, opioids, amphetamines, and any injection use) and current alcohol use practices. 
Clinical characteristics-Clinical data were abstracted using a standardized collection from medical records. Date of entry to clinic, prior HIV care, antiretroviral therapy (ART) initiation, and $\mathrm{CD}^{+}{ }^{+} \mathrm{T}$-lymphocyte count (CD4) and plasma HIV RNA viral loads at the first clinic visit and the date closest to the interview were recorded.

\section{Statistical analysis}

All survey and abstracted clinical data were double entered into a secure database.

Differences between immigrant and US-born Latinos were tested with the Pearson's $\mathrm{x}^{2}$ and Kruskal-Wallis tests for categorical and continuous variables, respectively. Behavioral data were stratified by sex in addition to region of birth. Data were analyzed using Stata vll.0 (StataCorp, College Station, TX).

Comparison with black and white patients-Behavioral and sociodemographic characteristics were compared with non-Latino HIV-infected UNC patients who were previously interviewed with the Clinical and Socio-demographic Survey (CSDS) from 1999 to 2011. The CSDS is a comprehensive face-to-face survey of clinical, demographic, and risk behaviors, implemented by the UNC Center for AIDS Research HIV Clinical Cohort (UCHCC) (Howe, Cole, Napravnik, \& Eron, 2010) and has been previously described (Brouwer, Napravnik, Smiley, Corbett, \& Eron, 2011). To date, 491 patients had participated in the CSDS, of which 345 (70\%) were black, 106 (22\%) white, 7 (1\%) English-speaking Latino, and 33 (7\%) were mixed/other race. We restricted our comparisons to the 451 black and white participants. Although the CSDS is a convenience sample, it is representative of the non-Latino UCHCC participants ( $n=2453$ by 2009), by race ( $70 \%$ CSDS vs. $62 \%$ UCHCC are black), and sex (61\% CSDS vs. $70 \%$ UCHCC are male).

\section{Results}

During the study period, 220 Latino patients had scheduled clinic visits, and of these, 163 (74\%) were approached for participation. Of the patients approached, $26(16 \%)$ refused citing lack of time, 5 (3\%) refused without reason, and $5(3 \%)$ could not provide consent due to illness or impaired cognition. In total, we interviewed 127 patients. Those patients not interviewed were similar to study participants by sex ( $76 \%$ vs. $74 \%$ male), age (median 39 vs. 37 years), and known immigrant status (79\% vs. $82 \%$ were foreign born).

\section{Sociodemographic and clinical characteristics}

Immigrant and US-born Latino participants differed by several sociodemographic and clinical factors (Table 1). In total, 104 (82\%) patients were immigrants and $23(18 \%)$ were US born. Both groups were predominately male ( $75 \%$ vs. $70 \%$ US born). Immigrants were more recently diagnosed (median year 2006 [IQR 2001-2008] vs. 2004 [IQR 1991-2007]; $P$ $=0.01)$, more likely to speak Spanish exclusively ( $82 \%$ vs. $4 \% ; P<0.001)$, and were less educated (49\% vs. $78 \%$ graduated high school; $P<0.001$ ) compared with US-born Latinos. The mean acculturation score was 2.34 (3.78 US born vs. 2.02 for immigrants) with $91 \%$ of the immigrants having low-acculturation levels. While no differences were seen in income, 95 (91\%) immigrants lacked any health insurance compared with $48 \%$ of US-born patients $(P<0.001)$. The overall rate of incarceration among both groups was high $(42 \%)$, 
particularly among men (49\% men vs. $9 \%$ of women reported ever being in jail or prison) (data collected but not shown in Table 1).

US-born Latinos were significantly more likely to report a history of illicit drug use (70\% vs. $18 \%$ immigrants; $P<0.001)$. The most commonly used substances were cannabis $(94 \%)$ and crack/cocaine (82\%). However, intravenous drug use was rare (four patients). Current alcohol consumption was similar between immigrant and US-born participants, with alcohol use reported by $56 \%(n=71)$. Thirty-eight percent of drinkers $(n=27)$ reported consuming $\geq 5$ drinks in a typical day of drinking.

Immigrants were significantly more likely to enter care with advanced HIV disease (Table 1). Among ART-naïve Latinos at entry $(n=101)$, immigrants had a lower median CD4 count (183 cells $/ \mathrm{mm}^{3}$ [IQR 64-342] vs. 371 [IQR 203-725] US born; $P=0.02$ ). At the time of interview, the immune status of both groups had improved from entry into care, but still tended to be lower among the immigrants $(P=0.08)$ likely reflecting their much lower CD4 counts on entry, as both groups had similar ART use ( $>90 \%$ for both). In addition, most Latinos in both groups were receiving ART and had RNA viral loads of $<50$ copies $/ \mathrm{mL}$ at the time of the interview (Table 1).

\section{Sexual risk behaviors}

We found several differences in reported risk behaviors between the immigrant and US-born Latinos when stratified by sex (Table 2). Among men, immigrants were less likely than nonimmigrants to report sex with men as their perceived mode of HIV exposure (41\% vs. $81 \%$; $P=0.01)$ and to identify as homosexual or bisexual (39\% vs. $75 \% ; P=0.04)$. Immigrant men were more likely to report sexual contact with women only (57\% vs. $19 \% ; P=0.006$ ), and fewer immigrant men reported sexual contact with both men and women (29\% vs. 50\%; $P=0.09)$ than US-born men. More immigrant men $(n=28)$ reported a history of paying for sex than US-born Latino men ( $36 \%$ vs. $19 \% ; P=0.25$ ). Among these 28 immigrant men, $89 \%$ reported sex with female sex workers and $60 \%$ had sex with non-Latina sex workers. Of these immigrant men, 14 reported that these encounters occurred in NC only, whereas the remainders reported that encounters occurred outside US only (6), in both locations (6), and in other states (2).

Among both men and women, immigrants reported significantly fewer lifetime partners (median 6 vs. 20 for US-born Latinos; $P=0.001$ ). Immigrant Latinas reported significantly fewer lifetime partners with a median of 3 (IQR 2-5) compared with 10 (IQR 4-50) among US-born Latinas $(P=0.03)$. Three of seven $(43 \%)$ of US-born Latinas reported history of exchanging sex for money or drugs and more reported past sexual assault when compared with immigrant Latinas (57\% vs. 19\%; $P=0.07$ ).

\section{Comparison with white and black patients}

Sexual risk behaviors among immigrant Latino men were most similar to HIV-infected black men who were previously interviewed with the CSDS (Table 2). A similar proportion of black men (45\%) reported sex with men as their perceived mode of exposure and most identified as heterosexual (55\%). Also, $31 \%$ of black men $(n=61)$, similar to immigrant 
Latino men (36\%), reported ever paying for sex which was significantly different than whites $(n=12,15 \% ; P<0.05)$. However, Latino immigrant men had fewer lifetime partners (both male and female) than non-Latino men (median 8 [IQR 4-25] vs. 18 [IQR 8-50] for blacks and 48 [IQR 20-120] for whites; $P<0.05$ ). On the other hand, US-born Latino men were similar to white men, who mostly reported sex with other men (82\%), identified as homosexual/bisexual (85\%) and by lifetime partners (median 35 [IQR 9-83] vs. 40 [IQR 16-100] for whites).

\section{Migration characteristics}

Among the 104 immigrants, most were born in Mexico (67\%) and Central America (30\%) (Table 3). Of 70 Mexican-born patients, most (84\%) originated in Southern or Central Mexican states and immigrated to the US in the past 15 years (median 1998 [IQR 19922002]). Most were also young adults at immigration with a median age of 24 (IQR 19-31) years; 90 (87\%) patients arrived in the US after age 14. In addition, most patients immigrated directly to NC without residing in any other US state and $75(72 \%)$ had never returned to their originating country. Very few patients (3\%) reported a long-term partner residing in their originating country.

The vast majority of immigrants (90\%) reported receiving their HIV diagnoses in the US and many (36\%) were diagnosed within 5 years of migration (Figure 1). For the 94 USdiagnosed patients, the median time from immigration to diagnosis was 8 years (IQR 0-12) and over two-thirds perceived acquiring HIV in the US.

\section{Discussion}

The Southeastern US has one of the fastest-growing Latino populations in the US, where Latinos are also disproportionately affected by HIV. Detailed information about this population will contribute to improvement in testing, linkage, and care. To our knowledge, this is the largest group of HIV-infected Latinos described in detail to date who are residing in the Southeast, a new Latino settlement area and also the US region with the largest burden of AIDS cases (Centers for Disease Control and Prevention, 2010). We found significant differences in clinical, risk behavior, and sociodemographic features between immigrant and US-born Latinos. Most Latinos receiving care in our clinics are immigrants who were less educated and more likely to be uninsured compared with their US-born counterparts. In addition, most immigrants were monolingual Spanish speakers with low levels of acculturation. These substantial socioeconomic barriers to navigating medical care among immigrants are compounded by their residence in a new Latino settlement area, where culturally and linguistically acceptable services may not be fully established.

Immigrant Latinos entered care with significantly more advanced immunosuppression than US-born Latinos. We have previously shown significantly lower CD4 counts among Latinos initiating care in our region (Dennis et al., 2011) with the current work further emphasizing this gap among immigrant Latinos. In our previous study, the median CD4 count among Latinos was 182 cells $/ \mathrm{mm}^{3}$, significantly lower than both blacks and whites at 302 and 292 cells $/ \mathrm{mm}^{3}$, respectively. The lower counts in Latinos appear to be driven by the large proportion of immigrants among this group. Other studies have reported immigrant status as 
a risk factor for late presentation (Borghi et al., 2008; Delpierre et al., 2007; Espinoza, Hall, \& Hu, 2009; Levy et al., 2007), which could be due to lack of knowledge about local medical services, inability to access culturally acceptable services, or perhaps false perception of low HIV risk among immigrants. In our current study, only $12 \%$ of immigrants endorsed delaying care more than 6 months after diagnosis, suggesting that late presentation among this group is largely due to late HIV testing. Once receiving care, median CD4 counts improved overall and the gap between immigrant and US-born Latinos decreased, emphasizing the success of therapy and similar engagement in care among both groups. This finding is consistent with other studies showing that most individuals receiving ART achieve undetectable HIV RNA viral loads (Das et al., 2010; Gill et al., 2010). In addition, another study found that Latinos lacking legal residency in Texas were more likely to present late to care, but once in care they had similar rates of virologic suppression compared with non-Latinos (Poon, Hartman, Davila, \& Giordano, 2010).

Nearly two-thirds of Latino immigrants in our study were diagnosed with HIV within 10 years of immigration. The advanced immunosuppression among immigrants suggests a longer duration of infection and may indicate that many infections could have occurred around the time of or in the first several years after immigration - a particularly vulnerable period for immigrants (Magis-Rodriguez, Lemp et al., 2009). An association between US migration and an increase in sexual behaviors while in the US has been reported among Mexicans (Levy et al., 2005; Magis-Rodriguez, Lemp et al., 2009; Parrado \& Flippen, 2010), illustrating the potential for initiation of riskier behavior by migrants once in the US. We found that most immigrant Latinos in our study arrived in the US during adolescence or young adulthood, a time of sexual initiation and higher risk sexual behavior. Additionally, over one-third of immigrant men reported a history of paying for sex, most of which occurred in the US. The low levels of acculturation seen among immigrants in our study may have an impact on risk of HIV acquisition; low levels have been associated with less condom use and less communication between sexual partners (Hernandez, Zule, Karg, Browne, \& Wechsberg, 2012; Rojas-Guyler, Ellis, \& Sanders, 2005; Shedlin, Decena, \& Oliver-Velez, 2005). Additionally, the low acculturation may also present a substantial barrier to accessing HIV testing (Kinsler et al., 2009) and thus may contribute to the late presentation seen among immigrants in our study.

Overall, immigrants reported different risk behaviors and were more likely to identify as heterosexual compared with US-born Latinos. Of immigrant men in our study, 43\% reported ever having sex with men. This may be lower than expected, as most immigrants in our study were of Mexican origin, and among Mexican-born men in the US, sex with men is the predominant mode of transmission (55\%) (Espinoza, Hall, Selik, \& Hu, 2008). Although Mexico has a concentrated HIV epidemic mostly among men who have sex with men (MSM), a shift to more AIDS diagnoses among heterosexuals has been reported, primarily in migrant sending regions (Magis-Rodriguez, Gayet et al., 2004; Magis-Rodriguez, Lemp et al., 2009). Notably, nearly one-third of AIDS cases in Mexico are reported in states ${ }^{1}$ sending

${ }^{1}$ Among the 10 states with highest mobility: Baja California, Colima, Guanajuato, Guerrero, Jalisco, Michoacán, Oaxaca, Puebla, San Luis Potosí, and Zacatecas. 
the most migrants to the US (Magis-Rodriguez, Gayet et al., 2004), suggesting a continued link between the HIV epidemic in Mexico and US migration.

Our study may be limited by decreased reporting of sensitive information due to social desirability bias, particularly among immigrants, though a Latino whose primary language is Spanish conducted all interviews. Both HIV and homosexuality are reportedly stigmatized in Latino cultures (Diaz, Ayala, Bein, Henne, \& Marin, 2001; Garland, Andrade, \& Page, 2010) and MSM activity may be underreported (Zellner et al., 2009). We found Latino immigrant men to be comfortable discussing their sexual histories, possibly because most have been asked sensitive questions as part of routine HIV-clinical care. While our study is also based on a convenience sample, three quarters of all Latino patients were approached, we had a very high participation rate, and our sample appears to be representative of the Latino clinic population.

Our study highlights the importance of approaching the Latino population as a heterogeneous minority group, particularly in the setting of HIV-infected individuals in the Southeastern US. Immigrants face a number of socioeconomic barriers to care and most entered care with advanced HIV disease. Fortunately, once in care both immigrant and USborn Latinos had similar rates of ART usage and success with therapy. This observation stresses the need for programs to identify immigrant Latinos earlier in the course of their HIV infection and address some of the barriers faced by this population in accessing testing and prevention services shortly after immigration. While a significant proportion of immigrants were MSM, most identified as heterosexual. This finding suggests that solely risk-based prevention services may not successfully reach many of these individuals and that recommendations for universal HIV testing (Branson et al., 2006) should continue to be endorsed for this group. However, discerning how best to reach immigrants, who may be socially marginalized and fear deportation, is of paramount importance for screening to successfully identify infected persons early in their course of infection. Innovative ways of offering HIV testing for Latino immigrants, especially shortly after arrival in the US, are needed. Prevention and care strategies in the region should also include culturally acceptable linkage and retention programs targeted toward the different needs of immigrant and USborn Latinos.

\section{Acknowledgments}

We thank the patients and staff at the UNC Infectious Disease clinic and the Wake and Durham County Health Department clinics; Dr. Arlene Seña for her review of the survey instrument; and Catherine Grodensky and Dr. Carol Golin at the UNC Center for AIDS Research Behavioral Core for consultation and review of the survey instrument.

This work was supported by the University of North Carolina at Chapel Hill Center for AIDS Research (P30 AI50410), the KL2 Multidisciplinary Clinical Research Development Award (5KL2RR025746-04) from the University of North Carolina at Chapel Hill, and the National Center for Research Resources (UL1RR025747).

\section{References}

Borghi V, Girardi E, Bellelli S, Angeletti C, Mussini C, Porter K, Esposito R. Late presenters in an HIV surveillance system in Italy during the period 1992-2006. Journal of Acquired Immune Deficiency Syndromes. 2008; 49(3):282-286.10.1097/QAI.O-b013e318186eabc [PubMed: 18845959] 
Branson BM, Handsfield HH, Lampe MA, Janssen RS, Taylor AW, Lyss SB, Clark JE. Revised recommendations for HIV testing of adults, adolescents, and pregnant women in health-care settings. Morbidity and Mortality Weekly Report Recommendations and Reports. 2006; 55(RR-14): 1-17. rr5514al. [PubMed: 16988643]

Brouwer ES, Napravnik S, Smiley SG, Corbett AH, Eron JJ Jr. Self-report of current and prior antiretroviral drug use in comparison to the medical record among HIV-infected patients receiving primary HIV care. Pharmacoepidemiology and Drug Safety. 2011; 20(4):432-439.10.1002/pds. 2096 [PubMed: 21294218]

Centers for Disease Control and Prevention. HIV surveillance report, 2009. 2010; 21 Retrieved from http://www.cdc.gov/hiv/topics/surveillance/resources/reports/.

Das M, Chu PL, Santos GM, Scheer S, Vittinghoff E, McFarland W, Colfax GN. Decreases in community viral load are accompanied by reductions in new HIV infections in San Francisco. PLoS One. 2010; 5(6):11068.10.1371/journal.pone.0011068

Delpierre C, Dray-Spira R, Cuzin L, Marchou B, Massip P, Lang T, Lert F. Correlates of late HIV diagnosis: Implications for testing policy. International Journal of STD \& AIDS. 2007; 18(5):312317.10.1258/095646207780749709 [PubMed: 17524190]

del Rio C. Latinos and HIV care in the southeastern United States: New challenges complicating longstanding problems. Clinical Infectious Diseases. 2011; 53:488-489.10.1093/cid/cir440 [PubMed: 21844032]

Dennis AM, Napravnik S, Sena AC, Eron JJ. Late entry to HIV care among Latinos compared with non-Latinos in a Southeastern US cohort. Clinical Infectious Diseases. 2011; 53(5):480 487.10.1093/cid/cir434 [PubMed: 21844031]

Diaz R, Ayala G, Bein E, Henne J, Marin B. The impact of homophobia, poverty, and racism on the mental health of gay and bisexual Latino men: Findings from 3 US cities. American Journal of Public Health. 2001; 91(6):927-932.10.2105/ajph.91.6.927 [PubMed: 11392936]

Espinoza L, Hall HI, Hu X. Increases in HIV diagnoses at the U.S.-Mexico border, 2003-2006. AIDS Education \& Prevention. 2009; 21(5):19-33.10.1521/aeap.2009.21.5_supp.19 [PubMed: 19824832]

Espinoza L, Hall HI, Selik R, Hu X. Characteristics of HIV infection among Hispanics, United States 2003-2006. Journal of Acquired Immune Deficiency Syndromes. 2008; 49(1):94-101.10.1097/ QAI.Ob013e3181820129 [PubMed: 18667927]

Garland JM, Andrade AS, Page KR. Unique aspects of the care of HIV-positive Latino patients living in the United States. Current HIV/AIDS Reports. 2010; 7(3):107-116.10.1007/s11904-010-0049-1 [PubMed: 20526824]

Gill VS, Lima VD, Zhang W, Wynhoven B, Yip B, Hogg RS, Harrigan PR. Improved virological outcomes in British Columbia concomitant with decreasing incidence of HIV type 1 drug resistance detection. Clinical Infectious Diseases. 2010; 50(1):98-105.10.1086/648729 [PubMed: 19951169]

Hernandez AM, Zule WA, Karg RS, Browne FA, Wechsberg WM. Factors that influence HIV risk among Hispanic female immigrants and their implications for HIV prevention interventions. International Journal of Family Medicine. 2012; 2012:1-11.10.1155/2012/876381

Howe CJ, Cole SR, Napravnik S, Eron JJ. Enrollment, retention, and visit attendance in the University of North Carolina Center for AIDS Research HIV clinical cohort, 2001-2007. AIDS Research and Human Retroviruses. 2010; 26(8):875-881.10.1089/aid.2009.0282 [PubMed: 20672995]

Kinsler JJ, Lee SJ, Sayles JN, Newman PA, Diamant A, Cunningham W. The impact of acculturation on utilization of HIV prevention services and access to care among an at-risk Hispanic population. Journal of Health Care for the Poor and Underserved. 2009; 20(4):996-1011.10.1353/hpu.0.0204 [PubMed: 20168013]

Kochhar, R.; Suro, R.; Tafoya, S. The new Latino South: The context and consequences of rapid populaton growth Report. Washington, DC: Pew Hispanic Center; 2005. Retreived from http:// pewhispanic.org/nles/reports/50.pdf

Levy V, Page-Shafer K, Evans J, Ruiz J, Morrow S, Reardon J, McFarland W. HIV-related risk behavior among Hispanic immigrant men in a population-based household survey in low-income 
neighborhoods of northern California. Sex Transmit Disease. 2005; 32(8):487490.10.1097/01.olq.0000161185.06387.94

Levy V, Prentiss D, Balmas G, Chen S, Israelski D, Katzenstein D, Page-Shafer K. Factors in the delayed HIV presentation of immigrants in Northern California: Implications for voluntary counseling and testing programs. Journal of Immigrant and Minority Health/Center for Minority Public Health. 2007; 9(1):49-54.10.1007/s10903-006-9015-9 [PubMed: 17031578]

Magis-Rodriguez C, Gayet C, Negroni M, Leyva R, Bravo-Garcia E, Uribe P, Bronfman M. Migration and AIDS in Mexico: An overview based on recent evidence. Journal of Acquired Immune Deficiency Syndromes. 2004; 37(Suppl 4):S215-226. Retrieved from http://europepmc.org/ abstract/MED/15722864. [PubMed: 15722864]

Magis-Rodriguez C, Lemp G, Hernandez MT, Sanchez MA, Estrada F, Bravo-Garcia E. Going North: Mexican migrants and their vulnerability to HIV. Journal of Acquired Immune Deficiency Syndromes. 2009; 57(Suppl 1):S21-25.10.1097/QAI.Ob013e3181a26433 [PubMed: 19384097]

Marin G, Sabogal F, Marin BV, Otero-Sabogal R, Perez-Stable EJ. Development of a Short Acculturation Scale for Hispanics. Hispanic Journal of Behavioral Sciences. 1987; 9(2):183205.10.1177/07399863870092005

NC Department of Health and Human Services. 1999 STD surveillance report. 2000. Retrieved from http://www.epi.state.nc.us/epi/hiv

NC Department of Health and Human Services. Epidemiologic profile for HIVJSTD prevention \& care planning, 2009. 2010. Retrieved from http://www.epi.state.nc.us/epi/hiv/

Painter T. Connecting the dots: When the risks of HIV/STD infection appear high but the burden of infection is not known - the case of male Latino migrants in the Southern United States. AIDS and Behavior. 2008; 12(2):213-226.10.1007/s10461-007-9220-0 [PubMed: 17373586]

Parrado EA, Flippen CA. Migration and sexuality: A comparison of Mexicans in sending and receiving communities. Journal of Social Issues. 2010; 66(1):175-195.10.1111/ j.1540-4560.2009.01639.x [PubMed: 20454599]

Pew Hispanic Center. Demographic profile of Hispanics in North Carolina, 2010. 2010. Retrieved from http://www.pewhispanic.org/states/state/nc/

Poon, K.; Hartman, C.; Davila, J.; Giordano, T. Healthcare disparities: How does race and legal residency affect outcomes in HIV/AIDS?; Paper presented at the 48th Annual Meeting of the Infectious Diseases Society of America; Vancouver, BC, Canada. 2010 Oct.

Rojas-Guyler L, Ellis N, Sanders S. Acculturation, health protective sexual communication, and HIV/ AIDS risk behavior among Hispanic women in a large midwestern city. Health Education \& Behavior. 2005; 32(6):767-779.10.1177/1090198105277330 [PubMed: 16267147]

Shedlin MG, Decena CU, Oliver-Velez D. Initial acculturation and HIV risk among new Hispanic immigrants. Journal of the National Medical Association. 2005; 97(7 Suppl):32S-37S. Retrieved from http://www.ncbi.nkn.nih.gov/pmc/articles/PMC2640649/. [PubMed: 16080455]

Zellner JA, Martinez-Donate AP, Sañudo F, Fernandez-Cerdeño A, Sipan CL, Hovell MF, Carrillo H. The interaction of sexual identity with sexual behavior and its influence on HIV risk among Latino men: Results of a community survey in northern San Diego County, California. American Journal of Public Health. 2009; 99(1):125-132.10.2105/AJPH.2007.129809 [PubMed: 19008512] 


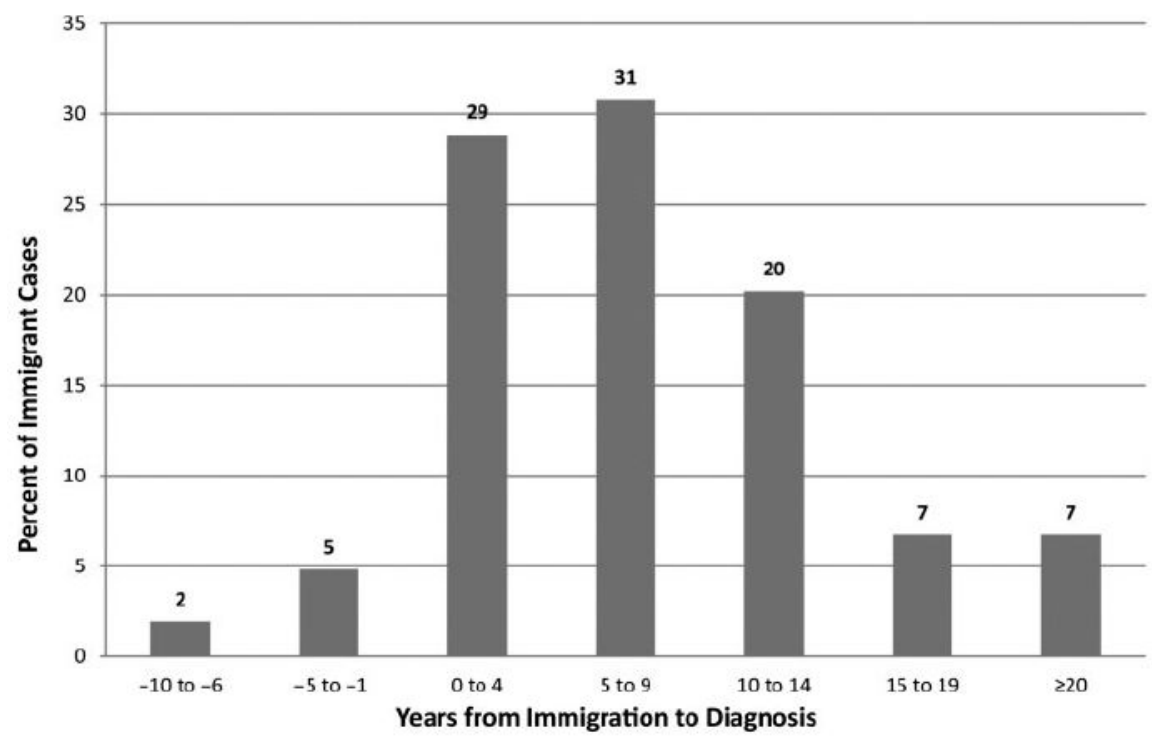

Figure 1.

Years elapsed from first immigration to HIV diagnosis among 104 Latino immigrants. Over $50 \%$ of cases were diagnosed within 10 years of immigration. 


\section{Table 1}

Sociodemographic and clinical characteristics of $127 \mathrm{HIV}$-infected foreign and US-born Latinos compared with $451 \mathrm{HIV}$-infected black and white patients receiving care at the University of North Carolina.

\begin{tabular}{|c|c|c|c|c|}
\hline Characteristic & Latino immigrant \% $(n / N)$ & $\begin{array}{c}\text { Latino US born\% } \\
\qquad(n / N)\end{array}$ & Black\% $(n / N)$ & White\% $(n / N)$ \\
\hline Overall & $N=104$ & $N=\mathbf{2 3}$ & $N=345$ & $N=106$ \\
\hline \multicolumn{5}{|l|}{ Sociodemographic } \\
\hline Age, median years $(\mathrm{IQR})^{\dagger+}$ & $37(30-44)$ & $39(27-50)$ & $43(38-50)$ & $44(37-48)$ \\
\hline Male $^{\dagger}$ & $75(78 / 104)$ & $70(16 / 23)$ & $58(199 / 345)$ & $76(81 / 106)$ \\
\hline \multicolumn{5}{|l|}{ Years since diagnosis ${ }^{\dagger *}$} \\
\hline 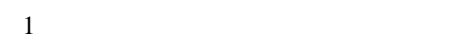 & $23(24 / 104)$ & $4(1 / 23)$ & $9(30 / 336)$ & $7(7 / 105)$ \\
\hline $2-5$ & $35(36 / 104)$ & $39(9 / 23)$ & $25(83 / 336)$ & $20(21 / 105)$ \\
\hline$>5$ & $42(44 / 104)$ & $57(13 / 23)$ & $66(223 / 336)$ & $73(77 / 105)$ \\
\hline Delayed care $>6$ months after diagnosis & $12(12 / 104)$ & $9(2 / 23)$ & $18(46 / 249)$ & $16(13 / 80)$ \\
\hline High school graduate ${ }^{* \dagger \neq}$ & $49(51 / 104)$ & $78(18 / 23)$ & $67(231 / 345)$ & $89(94 / 106)$ \\
\hline Annual income $<\$ 10,000^{\ddagger}$ & $54(56 / 104)$ & $39(9 / 23)$ & $63(212 / 334)$ & $38(39 / 104)$ \\
\hline Any insurance (private or Medicaid) ${ }^{*}+\hbar$ & $9(9 / 104)$ & $52(12 / 23)$ & $52(178 / 343)$ & $58(62 / 106)$ \\
\hline History of illicit drug use $*+\hbar$ & $17(18 / 103)$ & $70(16 / 23)$ & $64(210 / 329)$ & $64(67 / 104)$ \\
\hline Ever in jail or prison & $38(40 / 104)$ & $39(9 / 23)$ & $43(146 / 342)$ & $30(32 / 106)$ \\
\hline In married/committed relationship ${ }^{\dagger t}$ & $55(57 / 104)$ & $43(10 / 23)$ & $20(47 / 233)$ & $26(19 / 73)$ \\
\hline Currently employed & $71(71 / 100)$ & $52(12 / 23)$ & - & - \\
\hline Monolingual Spanish ${ }^{*}$ & $82(85 / 104)$ & $4(1 / 23)$ & - & - \\
\hline Low acculturation $*$ & $92(96 / 104)$ & $4(1 / 23)$ & - & - \\
\hline \multicolumn{5}{|l|}{ Clinical } \\
\hline History of any STI* & $41(43 / 104)$ & $65(15 / 23)$ & $52(180 / 345)$ & $40(42 / 106)$ \\
\hline ART-naïve at entry* & $84(86 / 102)$ & $65(15 / 23)$ & - & - \\
\hline \multicolumn{5}{|c|}{ CD4 Lymphocyte count, median cells $/ \mathrm{mm}^{3}$ (IQR) } \\
\hline Entry to clinic ${ }^{*}$ & $187(60-342)$ & $371(296-509)$ & - & - \\
\hline Entry to clinic and ART-naïve ${ }^{*}$ & $183(64-342)$ & $371(203-725)$ & - & - \\
\hline Current & $400(249-565)$ & $471(391-730)$ & - & - \\
\hline \multicolumn{5}{|l|}{ RNA viral load, median log copies/mL } \\
\hline Entry to clinic and ART-naïve & $4.7(4.1-5.3)$ & $4.9(3.6-5.0)$ & - & - \\
\hline Current & $1.7(1.6-2.2)$ & $1.7(1.6-2.7)$ & - & - \\
\hline On ART & $95(99 / 104)$ & $91(21 / 23)$ & - & - \\
\hline RNA $<50$ copies $/ \mathrm{mL}$ & $62(61 / 98)$ & $76(16 / 21)$ & - & - \\
\hline
\end{tabular}

Notes: Varying denominators reflect missing data for that question. Differences were tested between groups using Pearson's $\mathrm{x}^{2}$ for categorical variables or Kruskal-Wallis for continuous variables.

STI, sexually transmitted infection; ART, antiretroviral therapy.

${ }^{a}$ Per patient report: Chlamydia, Gonorrhea, Trichomonas, Syphilis, Genital warts, Genital Herpes. 
${ }^{*}<0.05$ immigrant Latino vs. US-born Latinos.

${ }^{\dagger} P<0.05$ immigrant Latinos vs. Blacks.

${ }_{P}<0.05$ immigrant Latino vs. Whites. 
Table 2

Sexual ris behaviors among $127 \mathrm{HIV}$-infected foreign and US-born Latinos compared with $451 \mathrm{HIV}$-infected black and white patients receiving care at the Univeristy of North Carolina.

\begin{tabular}{|c|c|c|c|c|}
\hline Characteristic & Latino immigrant \% $(n / N)$ & Latino US born \% $(n / N)$ & $\operatorname{Black} \%(n / N)$ & White\% $(n / N)$ \\
\hline Men & $N=78$ & $N=16$ & $N=199$ & $N=\mathbf{8 1}$ \\
\hline \multicolumn{5}{|l|}{ Perceive mode of exposure ${ }^{a}$} \\
\hline Sex with men ${ }^{* t}$ & $41(32 / 78$ & $81(13 / 6)$ & $45(89 / 199)$ & $81(66 / 81)$ \\
\hline Sex with women $*+\xi$ & $64(50 / 78)$ & $25(4 / 16)$ & $49(97 / 199)$ & $20(16 / 81)$ \\
\hline Shared needles ${ }^{\dagger}$ & $5(4 / 78)$ & $6(1 / 16)$ & $26(51 / 199)$ & $6(5 / 81)$ \\
\hline Other/unknown & $5(4 / 78)$ & $0(0 / 16)$ & $4(7 / 199)$ & $6(5 / 81)$ \\
\hline \multicolumn{5}{|l|}{ Sexual orientation ${ }^{\frac{1}{t}}$} \\
\hline Heterosexual & $54(41 / 76)$ & $25(4 / 6)$ & $55(109 / 199)$ & $15(12 / 80)$ \\
\hline Homosexual & $33(25 / 76)$ & $63(10 / 16)$ & $32(63 / 199)$ & $70(56 / 80)$ \\
\hline Bisexual & $7(5 / 76)$ & $13(2 / 16)$ & $11(21 / 199)$ & $15(12 / 80)$ \\
\hline Unsure & $7(5 / 76)$ & $0(0 / 16)$ & $3(6 / 199)$ & $0(0 / 80)$ \\
\hline Total lifetime partners, ${ }^{* \dagger+}$ median (IQR) & $8(4-25)$ & $24(10-81)$ & $18(8-50)$ & $48(20-120)$ \\
\hline Age at first sex ${ }^{*}$, median vears (IQR) & $15(14-18)$ & $14(13-17)$ & $15(13-17)$ & $16(14-17)$ \\
\hline \multicolumn{5}{|l|}{ Sex with men } \\
\hline Ever $^{*+}$ & $43(33 / 77)$ & $81(13 / 16)$ & $44(30 / 68)$ & $82(23 / 28)$ \\
\hline Lifetime partners, ${ }^{*}$ median $(\mathrm{IQR})$ & $18(4-50)$ & $35(9-83)$ & $10(5-45)$ & $40(16-100)$ \\
\hline \multicolumn{5}{|l|}{ Sex with women } \\
\hline Ever & $86(67 / 78)$ & $69(11 / 16)$ & $91(62 / 68)$ & $89(25 / 28)$ \\
\hline Lifetime partners, ${ }^{\dagger}$ median (IQR) & $5(2-8)$ & $10(2-20)$ & $10(3-25)$ & $4(2-20)$ \\
\hline Paid for sex (ever) & $36(28 / 78)$ & $19(3 / 16)$ & $31(61 / 197)$ & $15(12 / 81)$ \\
\hline Exchanged sex for money or goods (ever) ${ }^{*+t}$ & $4(3 / 78)$ & $31(5 / 16)$ & $25(50 / 198)$ & $19(15 / 81)$ \\
\hline Sexually assaulted (ever) ${ }^{*+}$ & $14(11 / 77)$ & $19(3 / 16)$ & $29(24 / 83)$ & $49(20 / 41)$ \\
\hline Women & $N=26$ & $N=7$ & $N=116$ & $N=25$ \\
\hline \multicolumn{5}{|l|}{ Perceived mode of exposure ${ }^{a}$} \\
\hline Sex with men & $85(22 / 26)$ & $71(5 / 7)$ & $88(128 / 146)$ & $84(21 / 25)$ \\
\hline Sex with women & $0(0 / 26)$ & $0(0 / 7)$ & $1(1 / 146)$ & $0(0 / 25)$ \\
\hline Shared needles & $4(1 / 26)$ & $29(2 / 7)$ & $15(22 / 146)$ & $8(2 / 25)$ \\
\hline Other/unknown & $15(4 / 26)$ & $14(1 / 7)$ & $6(9 / 146)$ & $16(4 / 25)$ \\
\hline \multicolumn{5}{|l|}{ Sexual orientation } \\
\hline Heterosexual & $88(21 / 24)$ & $100(7 / 7)$ & $95(138 / 146)$ & $100(25 / 25)$ \\
\hline Homosexual & $4(1 / 24)$ & $0(0 / 7)$ & $1(1 / 146)$ & $0(0 / 25)$ \\
\hline Bisexual & $4(1 / 24)$ & $0(0 / 7)$ & $4(6 / 146)$ & $0(0 / 25)$ \\
\hline Unsure & $4(1 / 24)$ & $0(0 / 7)$ & $1(1 / 146)$ & $0(0 / 25)$ \\
\hline Total lifetime partners, ${ }^{*}+$ median (IQR) & $3(2-5)$ & $10(4-50)$ & $10(5-20)$ & $11(5-25)$ \\
\hline Age at first sex, median years (IQR) & $16(15-20)$ & $17(16-17)$ & $16(15-18)$ & $16(16-18)$ \\
\hline
\end{tabular}




\begin{tabular}{|c|c|c|c|c|}
\hline Characteristic & Latino immigrant \% $(n / N)$ & Latino US born \% $(n / N)$ & Black\% $(n / N)$ & White\% $(n / N)$ \\
\hline Men & $N=\mathbf{7 8}$ & $N=16$ & $N=199$ & $N=\mathbf{8 1}$ \\
\hline \multicolumn{5}{|l|}{ Sex with men } \\
\hline Ever & $100(25 / 25)$ & $86(6 / 7)$ & $100(66 / 66)$ & $100(16 / 16)$ \\
\hline Lifetime partners, ${ }^{*}+\neq$ median (IQR) & $3(2-4)$ & $20(5-50)$ & $10(5-20)$ & $10(5-25)$ \\
\hline \multicolumn{5}{|l|}{ Sex with women } \\
\hline Ever & $8(2 / 25)$ & $14(1 / 7)$ & $11(7 / 66)$ & $19(3 / 16)$ \\
\hline Lifetime partners, median (IQR) & $2(1-3)$ & $2(2-2)$ & $2(1-3)$ & $1(1-1)$ \\
\hline Paid for sex (ever) & $0(0 / 26)$ & $0(0 / 7)$ & $4(6 / 146)$ & $4(1 / 25)$ \\
\hline Exchanged sex for money or goods (ever) $*+$ & $4(1 / 26)$ & $43(3 / 7)$ & $32(47 / 145)$ & $24(6 / 25)$ \\
\hline Sexually assaulted (ever) ${ }^{\dagger t}$ & $19(5 / 26)$ & $57(4 / 7)$ & $60(55 / 91)$ & $57(12 / 21)$ \\
\hline
\end{tabular}

Notes: Varying denominators reflect missing data for that question. Difference were tested between groups using Pearson's $\mathrm{x}^{2}$ for categorical variables or Kruskal-Wallis for continuous variables.

${ }^{a}$ Self-identified. Patients may be included in more than one category.

${ }_{P}^{*}<0.05$ immigrant Latinos vs. US-born Latinos.

${ }^{\dagger} P<0.05$ immigrant Latinos vs Blacks.

${ }_{P}<0.05$ immigrant Latinos vs. Whites. 
Table 3

Migration characteristics of 104 HIV-infected Latino immigrants.

\begin{tabular}{|c|c|}
\hline Characteristic & $n(\%)$ \\
\hline \multicolumn{2}{|l|}{ Country of Birth } \\
\hline \multicolumn{2}{|l|}{ Mexico, region } \\
\hline Southern ${ }^{a}$ & $38(37)$ \\
\hline North and South Central ${ }^{b}$ & $21(20)$ \\
\hline Western $c$ & $5(5)$ \\
\hline Northern $d$ & $6(6)$ \\
\hline Central America $e$ & $31(30)$ \\
\hline South America $f$ & $3(3)$ \\
\hline Immigrated directly to North Carolina & $60(58)$ \\
\hline \multicolumn{2}{|l|}{ Age at immigration, years } \\
\hline$<15$ & $14(13)$ \\
\hline $15-29$ & $58(56)$ \\
\hline 230 & $32(31)$ \\
\hline Ever returned to originating country & $29(28)$ \\
\hline Spouse/partner currently residing in country of origin & $3(3)$ \\
\hline HIV diagnosis outside US & $10(10)$ \\
\hline \multicolumn{2}{|l|}{ Time from immigration to diagnosis, years $g$} \\
\hline $0-1$ & $6(6)$ \\
\hline $1-5$ & $26(28)$ \\
\hline $6-10$ & $35(37)$ \\
\hline$>10$ & $27(29)$ \\
\hline \multicolumn{2}{|l|}{ Perceivd country of infection } \\
\hline US & $67(64)$ \\
\hline Outside US & $23(22)$ \\
\hline Not sure & $14(13)$ \\
\hline
\end{tabular}

Notes:

${ }^{a}$ Southern region includes Chiapas, Guerrero, Oaxaca, Tabasco, and Veracruz.

${ }^{b}$ North and South central region includes Distrito Federal, Guanajuato, Mexico, Puebla, and San Luis Potosi.

${ }^{c}$ Western region includes Jalisco, Michoacán, and Nayarit.

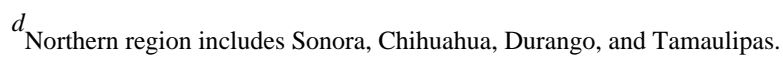

${ }^{e}$ Central America: 14 Honduras, 8 El Salvador, 5 Guatemala, 2 Costa Rica, and 2 Panama.

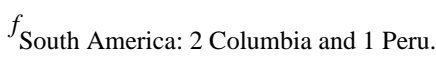

${ }^{g}$ Among the 94 patients diagnosed in the US. 